\title{
Socio-cultural impediments automation in Indian mines
}

\author{
M. Kumar \\ Indian Institute of Technology Madras, Chennai, Tamil Nadu, India
}

\begin{abstract}
Mining is an age-old industry that has propelled human progress and development. Despite India's economic prowess and richness in minerals, its mines are plagued with inefficiency and lack modern technology. In countries with well-developed mining industries, automation has proven to be a beneficial technology. Incorporating modern technologies into Indian mines is a challenging task due to many factors unique to the country. This study establishes the benefits of automation by discussing the Australian mining industry. A clear insight into the socio-cultural challenges to be faced while modernizing the Indian mining industry, focusing on automation, is presented using an interpretive approach, relying mainly on qualitative data in existing texts. The study conveys the significance of these obstacles and proposes new government bodies and schemes to overcome them. Finally, further work on this less discussed topic is motivated by mentioning areas for future consideration.
\end{abstract}

\section{Introduction}

India has a rich tradition in mining that can be traced back to the $3^{\text {rd }}$ millennium BCE. Over the years, mining activities of the nation have fuelled its progress - from sustenance to development. India is endowed with plentiful supplies of natural resources. The country has vast reserves of coal, bauxite, iron ore, manganese ore, mica, chromites, natural gas, diamonds, limestone, and thorium. It is estimated that there are nearly a hundred minerals extracted and used in significant quantities. The industry morphed into its current avatar after the nation's independence in 1947. Mining is a major economic activity in the country. It has a good contribution to the gross domestic product (GDP) of the industrial sector and serves as the backbone of several other industrial activities of the nation. India has over three thousand mines. The mining industry also provides jobs to about 2.3 million individuals [1]. 
In 2018, India was the 5th largest producer of minerals based on volume and 8th largest based on value. India ranks 2 nd in barytes and steam coal, 3rd in chromates, feldspar and bentonite, 4th in iron ore and aluminum, 5th in zinc and crude bauxite, 6th in bauxite, and 7th in manganese ore based on the production of minerals during 2017-2018 [2]. Over the last few decades, India's mining sector has steadily grown due to supportive legal reforms and the increasing demands for minerals, fuel, and resources.

However, many problems plague the mining industry. The industry has a poor reputation in terms of human rights violations and rampant pollution. The interests of the local communities affected by mining operations are often neglected or not given enough importance. Many of the measures to prevent environmental damage are not enforced strictly. There have been several instances of corruption and ignorance, especially in recent times [3]. Apart from these problems, of interest in this study is the dwindling contribution of the mining industry to the nation's GDP. This is a major economic problem. In 1992-1993, the sector contributed 3.4\% to the national GDP. In 1999-2000, this figure dropped down to 3\%. This was followed by $2.3 \%$ in $2009-2010,1.93 \%$ in $2012-2013$, and a meager $1.53 \%$ in $2017-2018$ [4]. This alarming statistic shows that the mining industry is not keeping up with the development of the country and its other industries. Mining is a backbone industry that supports industries such as power plants, iron and steel plants, and fertilizer industries. A slowdown in the mining industry is also harmful to industries dependent on it. This is reflected in India being a net importer of minerals despite being a mineral-rich nation. Compared to strong mining economies such as Australia (6.99\% contribution to GDP) and South Africa (7.4\% contribution to GDP), India has a long way to go [4].

Against this backdrop, improving the mining sector is very important. The introduction of modern technologies in this industry will play a key role to accomplish this goal. An improved mining sector will strengthen the industries that are dependent on it. This will be reflected in the growth of the economy and the contribution of mining to the nation's GDP. The dependence of the country on imports will also reduce. Another aspect that has not been discussed yet is the improvement of human resources. With an improvement in the mining industry in the form of technological advancements, the miners' health and safety will get better. Such advancements and implementation of modern technologies will make the industry more lucrative to modern youth, which will have far-reaching consequences in the long run. Taking all of these into account, automation is a viable option to improve the situation of the Indian mines. Moreover, this has already been implemented in other parts of the world, which can be improvised and emulated in India.

Despite the benefits of technology being recognized, the nation's mines have not been infused with modernity and state-of-the-art practices. Little has been done to implement an industry-wide advancement in technology. Traces of modernity are visible almost exclusively in large-scale mining operators such as Coal India Limited, Hindustan Zinc and Tata Steel Limited [5]. There are myriad reasons for the lack of technology ranging from legal, bureaucratic, regulatory, monetary, social and cultural factors. This study 
elucidates the social and cultural factors that impede the introduction of automation (and, in general, technological advancements) to the Indian mines. The study describes how and why socio-cultural factors are indeed a relevant impediment to modern technologies in the mining sector. Furthermore, it explains what can be done to overcome these challenges and facilitate a smooth transition into modernizing the industry, keeping in mind the interests of all stakeholders.

At a time when the nation's mining industry has realized the benefits of technology and is looking to espouse modernity, the study's ultimate goal is to ensure that socio-cultural factors do not hinder this paradigm shift. Currently, limited literature is available discussing the socio-cultural challenges associated with technological advancements in the mining industry. An overview of various problems is available in a report by Deloitte [1]. Technological problems are discussed in a report by Mishra, Ganguly\&Vidyadharan[5]. A brief mention of socio-cultural challenges for modern technologies mining can be found in a report by YES BANK \& ASSOCHAM [6]. A detailed review solely on the human rights issues that elucidates some social problems is provided in a report by the Human Rights Watch [3]. The current article seeks to draw attention towards serious consideration of socio-cultural factors that are generally overlooked in the Indian industry and looks to motivate further studies on this topic. Negligence of these issues may lead to drastic consequences such as agitations, protests, and human rights violations. With adequate background studies and analyses, such circumstances can indeed be avoided.

The approach followed in this study is primarily based on interpretive methods of textual analyses of existing reports and articles. Most data is qualitative, but as evidenced, quantitative data is provided at appropriate locations to underscore key points. The Indian mining industry's current state has already been discussed with the help of earlier studies, reports, and statistics. The focus is now turned towards the main issues to be discussed as part of this study. Firstly, to establish the viability of automation, two case studies where automation has been successfully implemented are presented from the Australian mining industry. Next, the social and cultural problems and challenges that preclude automation in the Indian scenario are discussed. The results and discussion section categorically lists how the mentioned problems can be overcome in the Indian mining scenario. The article concludes by summarizing the findings of this work and suggesting topics for extending this study.

\section{Case studies: successful implementation of automation}

The success of automation in mining is exemplified by the Australian mining industry. Mining has been an essential part of the Australian economy for a long time. The most conspicuous example of the early economic exploitation of the nation's mines is perhaps the Australian gold rushes starting from the 1850s. After a mild slowdown in the first half of the twentieth century, the 
discovery of vast ores of several minerals led to the industry's resurgence. Since then, Australia has been an important contributor to the global mining industry [7]. To illustrate this quantitatively, the nation was the largest producer of iron ore and bauxite and the 2nd largest producer of gold in 2019 [8]. Other key elements in which Australia ranks in the top five in terms of production include nickel, uranium, opal, zinc and coal. The mining industry of the nation is technologically advanced. Investments in modernizing this industry were visible from the early 1990s. Two major drivers of this change include Australia's national science agency, namely the Commonwealth Scientific and Industrial Research Organisation (CSIRO), and a private multinational mining corporation Rio Tinto. The implementation of automation by either of these organizations, along with the benefits, is presented below.

\subsection{Longwall Automation System}

Coal extraction is a significant mining activity in Australia. As mentioned above, in 2019, Australia was the biggest net exporter and the fourth-largest producer of coal. Coal exports account for the nation's second-largest source of export income, after iron ore exports [9]. Moreover, the coal industry accounts for more than a quarter of employment and a similar share in the total revenue of Australia's mining industry [10]. In this regard, it is no surprise that improving these mines' productivity and safety has been one of the foremost goals of the CSIRO.

Longwall mining is a method of extracting coal predominant in about ninety percent of Australian mines [10]. It is an underground mining method that involves slicing a layer of coal about two kilometers long, two hundred meters wide and two meters high. Thanks to the mechanized process, the extraction is continuous and results in higher productivity levels compared to traditional methods [11]. However, this method directly exposes the miners to several hazards, such as proximity to heavy electric and hydraulic machinery, roof falls and explosive mine gases and dust. To improve the working conditions in longwall mines, the idea of automation has been explored since the 1950s. Practical problems that weren't solved impeded its deployment until the CSIRO overcame these in the 2000s $[2,12]$.

The deployment of automated longwall mining systems has resulted in several benefits. It improved the safety of the mines by allowing humans to operate the system from the surface. It has also improved productivity by minimizing human operation and concomitant human errors. The longwall system used also minimizes the time required for maintenance. The automation system is now used by over $70 \%$ of mines in Australia. It is also being adopted by several mines across the world $[2,12]$. The technology also promotes an open platform for improvements in the system by third-party vendors, which further enhances its development. It is safe to conclude that longwall automation provides a glimpse of a successful implementation of automation in the mining industry. 


\subsection{Rio Tinto Group}

The Rio Tinto Group is an Anglo-Australian multinational mining corporation. It is a major player in the metals and mining industry, and as of 2007, was the 2nd largest metals and mining corporation [13]. The corporation's mining operations incorporate state-of-the-art technologies under their trademarked scheme called "mine of the future". The corporation was one of the first few to start infusing technology into mining, with evidence of investments and collaborations dating back to the 1990s [14]. Since then, it has conducted extensive trials and testing, and these technologies are finally being deployed today. For example, the use of drones and remotely operated vehicles for diagnostics and terrain mapping increases the efficiency of the process. Another significant use of technology is integrating the mining processes: from maintaining extraction records to job shifts to service needs. This allows for resource optimization. Further examples include the use of analytics, artificial intelligence, automation, machine learning and automation. Of particular interest in this study is the successful use of automation.

The Rio Tinto's network of sixteen iron ore mines in the Pilbara region of Western Australia exemplifies the virtues of automation. The entire network is managed by a single operations center in Perth, which controls the automated systems across all mines. This minimizes the presence of humans in the mines, which in its turn improves safety and facilitates the above mentioned integration. The array of autonomous implements includes trucks, drills and trains. About one-third of the trucks across the Pilbara network are autonomous (as of 2020). In 2019, the corporation flagged off the world's first-ever autonomous automated heavy rail network. The latest addition to the iron ore mines of the Pilbara regions is the mine at Koodaideri, which is touted to be the smartest mine ever developed by the group.

The benefits of these investments are now becoming visible. The obvious benefits of automation include reduced exposure of miners to heavy machinery and the harsh mining environment. Rio Tinto claims that in 2018, its fleet of autonomous haul trucks operated for an additional 700 hours per truck when compared to conventional haul trucks. This, in its turn, resulted in a $15 \%$ reduction in costs. A $14 \%$ higher effective utilization of resources has been achieved in comparison to manned trucks. The autonomous train network of the company obviates the need to transport train operators to remote areas. The use of autonomous drills has increased availability when compared to manned drills by approximately $15 \%$. It also ensures a more efficient, consistent and predictable recovery of the ore, which reduces redrilling and extends the life of consumable tools (such as explosives) [15]. In conclusion, the Rio Tinto group exemplifies the potential commercial successes reaped if automation is rightly used. 


\section{Challenges in the introduction of automation and technology in India}

Among several factors, two primary problems have been recognized: the resistance of the mining community and the poor structure and organization of the Indian mining industry. The reasons behind factors, their impacts, and measures to remedy these challenges are discussed below.

\subsection{Community Resistance}

Mines all around the world support the livelihoods of associated mining communities. Once the minerals of a mine are to be harnessed, miners settle nearby. To support this population, additional services, such as healthcare, education and law enforcement are needed. This cycle continues, and a bustling community is created. This process is epitomized by the settlements that emerged during the California Gold Rush, such as Shasta and Bodie[16, 17]. In India, the city of Dhanbad is mainly dependent on its mining activities. In this way, mining supports the livelihood of many people - either through direct employment or through indirect means, as described above. In India, the mining industry directly employs around 2.3 million individuals [1]. It is safe to say that the number of people affected by mining activities well exceeds this estimate.

It is these communities that vehemently oppose the introduction of technology and especially automation [18]. From their perspective, such modern practices will endanger their job security. It is worth mentioning that not only the miners will get affected, but also the people providing services to support them. With a lack of job security, the community may disband, as seen in the case of the dilapidated towns of the California Gold Rush. In the worst situations, this may result in disruptive actions on the part of the community, which has already been observed with regard to human rights and environmental issues. While introducing technology, and, especially automation, this aspect must be carefully considered. Of course, it is acknowledged that automation entails conversion from a large quantity of low-skilled labor to a small quantity of high-skilled labor. Although this is desirable for the growth of the industry and the economy, the immediate interests of those affected must not be ignored.

In order to ensure a smooth transition from the current mines without automation to mines with state-of-the-art technology, ensuring the job security of the mining community is of paramount importance. While a small proportion of the affected can be retained in the mines after adequate training, the remaining population needs to be adequately supplied with jobs and compensations. As mentioned above, automation will increase the proportion of high-skilled labor at the cost of low-skilled labor. This is reminiscent of the introduction of machinery in agriculture around the world. However, the provision of job security is, at best, a necessary but short term solution. In the long run, the perception of technology needs to be changed. What is currently viewed as a job extinguisher needs to be perceived as a positive step towards 
the nation's growth. To this end, grassroots development is necessary. This needs to be done in the form of improving education (literacy rates remain mediocre in the nation) and awareness. By taking such steps, mining will effectively be transformed into a more lucrative industry. Simultaneously, the perception mentioned above will improve.

Indian citizens, particularly in undeveloped regions, have deep cultural, spiritual and traditional values. In several cases, this has hindered the adoption of modern technologies in the nation's rural areas [19]. Mining communities across the nation are likely to have varied religious and cultural inhibitions towards modern technologies such as automation. These factors must be considered, and thorough analyses in this regard need to be made before a major technological overhaul is planned in a particular mine.

\subsection{The poor structure of the industry}

The legal, regulatory, and social framework in which the mining industry operates is vital to ensure its success. Over the last few decades, several measures have been taken by the government to improve the industry. Examples of these include the economic reforms of 1991, the 1993 National Mineral Policy, and the recent Mines and Minerals Laws (Amendment) in 2020. However, the structure of the mining industry remains far from perfect.

The structure of Indian mining primarily comprises a large number of small mines and corporations. Due to this, the capital and resources of the industry are thinly spread over many companies. Due to a lack of surplus capital, investments in scientific and technological pursuits are not undertaken. This is in sharp contrast to the large mining corporations exemplified by the Australian mining scenario. Across the world, enormous companies like Rio Tinto, Glencore and Leighton Contractors carry out large scale mining operations supplemented by a cutting edge technological arsenal. In India as well, large corporations with sufficient scientific, technical and financial resources have begun experimenting with, and implementing advanced and environment-friendly practices. But smaller counterparts are unable to do so [5]. Smaller corporations continue using labor-intensive methods owing to the abundance of cheap manpower in India. Moreover, several illegal mining operations are run in the mineral-rich parts of India. In recent years, the reputation of this industry was tarnished by several high-profile mining scams. It is not the case that regulatory bodies and measures are absent in India, but, more precisely, a case of weak enforcement and regulation. Corruption and criminal control are rampant in parts of the nation. These problems accentuate the issue of motivating an industry-wide technological shift.

To remedy this unfavorable scenario, it is imperative to implement strong regulatory mechanisms backed up with competent institutions that oversee mining operations. A case in point is the 'Lokayukta' present in the Indian state of Karnataka. The Lokayukta is an anti-corruption ombudsman organization in several Indian states. A primary role of the Lokayukta is to 
investigate and address matters pertinent to corruption. In this respect, the Karnataka Lokayukta has been successful in weeding out corrupt mining operations. What distinguishes the Karnataka Lokayukta from other Lokayuktas and law enforcement agencies across the nation is its significant autonomy and power, preventing the organization from falling prey to corruption. A viable option to curb illegal mining operations in India is to strengthen the Lokayukta institutions in all states. Apart from this, taking inspiration from the large corporations in the nation which are implementing technology, the long-term goal must be to shift into a well-organized industry with large corporations that have significant capital.

\section{Results and discussions}

The above discussions categorically demonstrated the viability of automation in the mining industry and the vital role of socio-cultural factors that must be considered before the automation can be adapted in India. This section discusses proposals to ensure that the socio-cultural problems do not hinder India's transition into a modern mining industry. It is worth mentioning that with suitable improvisations, similar schemes can be applied to ensure the smooth introduction of other modern technologies in the mines.

In order to dissuade community resistance, it is recommended to set up a government body to monitor (at the level of individual mines) the introduction of automation into mines. The main responsibilities of this body are as follows: ensuring mining companies protect the jobs of the mining community, promoting modern technology while protecting the cultural and spiritual values of the community, and attending to their grievances during the transition. Before automation is introduced in a mine, the mining company must get a clearance from the proposed government body guaranteeing that they act in the mining community's best interests. Furthermore, the clearance must be granted only if analyzing the impacts of automation reveals an overall positive effect on the mining community. The company must agree to protect the job of its workers. As far as possible, semi-skilled and skilled workers must be retained and trained to operate the automated machines. To secure the livelihood of the remaining workers, job opportunities at the mining community need to be created by promoting another sector of the mining community. For example, a community may thrive on handicrafts and mining activities; hence, unskilled laborers can be directed towards the handicrafts industry. However, specific communities may be solely dependent on mining activities. In such cases, automation must not be introduced unless provisions for another occupation are created in the region (such as setting up a factory). If the company does not adhere to its promises, the government body must be endowed with adequate powers to take action on the defaulters.

Another aspect includes convincing the residents of the community that their interests will be given prime importance. There are several instances of false promises and namesake schemes to protect the community's interests [3]. The government body must gain the community's confidence before the 
move to switch to automated machines is made. Steps to be taken in this direction include spreading awareness through means such as door-to-door campaigns and posters. In certain instances, the community may be averse to modern technology as it may violate their traditional or spiritual values. In these cases, a thorough analysis may be required before a decision regarding modernization can be made. In the long run, changing such perceptions towards modern technologies requires change at the grassroots level. As mentioned, improving education and awareness, particularly about the mining sector and its technologies, are crucial. Specific discussions on spreading awareness and education deviate from the essence of this article and are not discussed.

Two proposals to improve the structure of the mining industry are now presented. As mentioned, several of the problems discussed in this regard are due to weak enforcement of existing rules and regulations. By ensuring the strict implementation of these, illegal corporations can be weeded out and replaced by existing larger corporations. It is proposed to set up a nationallevel institution under the Indian Bureau of Mines responsible solely for upholding the integrity of the mining industry. This institution will be analogous to the aforementioned 'Lokayukta', albeit on the national-level and specifically for mining-related issues. The proposed institution must work in close coordination with the state governments, which currently have most regulatory powers over their mineral resources. It must have considerable autonomy and significant power to deliver justice to mining operations at fault.

The second proposal pertains to inducing a shift into a mining industry with lesser but larger corporations having significant capital. In the long run, the government should incentivize large corporations to subsume smaller local corporations while ensuring a win-win situation for either party. Legal frameworks facilitating mergers can be established. Large corporations should collaborate with their smaller counterparts by providing them with modern implements and sharing the profits earned. Schemes to incentivize the use of technology and automation, especially among large corporations, must be established. Naturally, this will motivate an industry-wide technological shift.

On the other hand, the interests of the existing small scale mining operations must be considered in the short run. They must be empowered with technical and scientific advisory services to impel technological advancement not limited to automation. This will allow them to reap the benefits of technology, which will exhort them to grow and undertake modern initiatives.

\section{Conclusions}

Having established the Indian mining industry's current state, and the need for improvement with the help of reports and articles, the necessity of introducing modern technology in this industry is evident. With a particular 
focus on automation, case studies around the world prove that if implemented correctly, this technology is a viable solution to several problems regarding productivity and safety faced in Indian mines. Two such case studies have been discussed in this paper. However, implementing this technology in India is not straightforward. This study has identified and thoroughly discussed two socio-cultural challenges that will impede automation (and technological advancement in general) in the mining industry. The significance of these aspects, which were largely overlooked so far in the literature, has been conveyed. Furthermore, a coherent outline of establishing government bodies and empowering them to overcome these challenges and to facilitate the modernization of the mining industry has been presented.

The Indian mining industry has recognized the benefits of automation and technology. This places India on the brink of adopting automation and modern technology, where large investments into technology are expected to begin. Against this backdrop, this study has provided a perspicuous insight into the socio-cultural obstacles so that they can be tackled to ensure a smooth and quick transition.

To further extend this study, it is proposed to look specifically into relevant communities and corporations and their unique problems. As was briefly discussed, India's vast cultural and spiritual traditions necessitate a detailed region-wise analysis to ascertain more specific measures for introducing modern technologies in that area. In order to implement the proposals of the previous section, further rigorous analyses are needed. Such studies will help gain a more profound understanding of the challenges at hand, easing the modernization of the Indian mining industry.

\section{References}

1. Human Resource \& Skill Requirement Study for Indian Mining Sector. Deloitte,57,29-33 (2016)

2. J.C.Ralston, D.C.Reid, M.T. Dunn,D.W. Hainsworth Longwall automation: delivering enabling technology to achieve safer and more productive underground mining. International Journal of Mining Science and Technology,25(6), 865-876 (2015)

3. Human Rights Watch. Out of control: mining, regulatory failure and human rights in India, (2012)

4. A.K. DasMining's contribution to India's GDP falling, (2019)

5. A.Mishra, M.Ganguly, V.Vidyadharan Overview of legal and regulatory framework, technologies and best process practices,27, 33(2017)

6. YES BANK \& ASSOCHAM. MINING: Building a Sustainable Development Framework for Inclusive Growth,(2014)

7. B.McKay, I.Lambert, S. Miyazaki The Australian mining industry: from settlement to 2000, (2000) 
8. U.S. Geological Survey. Mineral commodity summaries 2020: U.S. Geological Survey, 71 (Washington D.C: United States Government Publishing Office,2020)

9. M.Cunningham, L.Van Uffelen, M. Chambers The changing global market for Australian coal, (2019)

10. ACIL Allen Consulting Pty Ltd. CSIRO's impact and value: an independent evaluation, 20-22.(2014)

11. Energy Information Administration. U.S. Department of Energy. EIA report: Longwall mining,vii(Darby:Diane Publishing Co,1995)

12. J.C.Ralston, C. O. Hargrave, M.T. Dunn Longwall automation: trends, challenges and opportunities. International Journal of Mining Science and Technology,27(5), 733-739 (2017)

13. R. Hotten History of Rio Tinto,(2007)

14. B. Wixted Innovation, disruption and the second economy of mining,(2019)

15. A.L. Matysek, B.S. Fisher Productivity and innovation in the mining industry. BAE Research Report 2016, 1, 24-36(Canberra, 2016)

16. E. Petersen In the shadow of the mountain: a short history of Shasta County, California, 29-36 (1965)

17. California State Parks. Bodie: State Historic Park, (Accessed November 2020)

18. K. Manjaparra Automation can lift India's mining to new heights but here's what stops it.(2020)

19. J.S. Verma Economic problems of modern India. Problems of Development, 66 (New Delhi: Allied Publishers Limited,1989) 